\title{
REFLEXIONES SOBRE ESPAÑA Y EL SÁHARA ${ }^{1}$
}

\section{Emilio González Ferrín}

Al oeste, el mar. Y al este, el jaț al-jawf, la "línea del terror", frontera natural por la que nomadeaban las tribus guerreras protegiendo, probablemente por tradición ancestral, a las tributarias de la costa. Se trata de los términos en que José Ramón Diego Aguirre, historiador y militar, se sitúa para hacer la más sincera historia del Sáhara ${ }^{2}$; una historia meditada, vivida y sentida en gran parte por el autor con, probablemente, la única necesaria subjetividad de la nostalgia; por lo que pudo haber sido y no fue para España y el pueblo saharaui debido a la lógica presión marroquí y la ausencia de un proyecto político español para el territorio. Sirvan las líneas que siguen como un descubrirnos ante sus imprescindibles páginas.

John Damis, en su visión sobre el conflicto del Sáhara occidental, hace una relación de sus ocho tópicos o mitos fundacionales ${ }^{3}$, y ya sabemos por Enmanuel Sivan cómo el tiempo transforma los mitos en verdades admitidas. Aprovechamos aquí los enunciados de Damis aventurando interpretaciones preliminares actualizadas:

Primer mito: la internacionalización del conflicto; o dicho de otro modo, que la cuestión del Sáhara ha sido en realidad un capítulo más de la Guerra Fría. Siendo un conflicto a todas luces regional por sus características de equilibrio de poderes o extensión de los hinterland marroquí y argelino, desde Rabat se dió siempre, no obstante, la impresión de que se combatía a la Unión Soviética por la procedencia del armamento polisario (vía Argel). Aceptando lo tendencioso de internacionalizar el conflicto, la única reserva a la apreciación de Damis es que el aspecto no analizado del conflicto, la descolonización por parte de España, sí pudo revestir en cierta medida los temores de una particular guerra fría en las postrimerías del régimen del general Franco. Decididos a evacuar el territorio, las exigencias políticas españolas de la época no reconocieron en el Frente Polisario -cuyas siglas significan Frente Popular $(P O)$ para la Liberación $(L I)$ de Saguia al-Hamra (SA) y Rio de Oro (RIO)- a un grupo capaz de asumir las

\footnotetext{
${ }^{1}$ El presente trabajo se preparó como informe para el Consejo de la Juventud de España, haciéndose públicas sus conclusiones en el Seminario El impacto de la globalización sobre las relaciones Norte-Sur en el ámbito mediterráneo (Universidad Internacional Menéndez y Pelayo, Sanlúcar de Barrameda, septiembre de 2000), dirigido por la profesora Gema Martín Muñoz.

${ }^{2}$ Diego Aguirre, José Ramón: Historia del Sáhara Español. La verdad de una traición. Madrid: Kaydeda Ediciones, 1988.

${ }^{3}$ Damis John: "The Western Sahara Conflict: Myths and Realities". The Middle East Journal, 37,2 (Spring 1983), 169-179. John Damis es autor de una monografía esencial sobre el Sáhara: Conflict in Northwest Africa: The Western Sahara Dispute.Stanford CA: Hoover Institution Press, 1983.
} 
prerrogativas de poder. Ante la perspectiva de un gobierno títere manejado por la república argelina, tácitamente se eligió el mal menor; la percibida como estable dominación jerifiana.

Segundo mito: divergencias en torno a los protagonistas en una larga trayectoria de exclusiones: cuando España sólo admitía tratar con el pueblo saharaui, Marruecos se declaraba parte integrante necesaria. Después, en el momento de la cesión del territorio, cuando Marruecos no admitía interferencias, Mauritania asumió la independencia del Sáhara como salvaguarda de su integridad territorial. Y por último, cuando en instancias internacionales se dirimía la cuestión, Argelia siempre quiso permanecer en un segundo plano activo para no ser acusada de reivindicaciones propias. En este sentido, la presencia, quizá internacionalmente obligada, de Argelia en las conversaciones, paradójicamente no haría sino legitimar en cierto modo la propaganda marroquí de la cuestión como mero litigio fronterizo con el vecino oriental.

Tercer mito: el origen de los resistentes saharauis. Para Marruecos, durante largos años el brazo armado del Frente Polisario no eran saharauis sino mercenarios argelinos, y sus dirigentes eran disidentes mauritanos o marroquíes. Los refugiados en Tinduf serían tuaregs de los alrededores huyendo de las sequías del Sahel. Justipreciando las versiones encontradas, lo cierto es que los líderes históricos del Frente procedían en su mayoría de la región marroquí de Tarfaya, si bien no es menos cierto que tal región había sido retrocedida por España a Marruecos con anterioridad en total desacuerdo de su población, desvinculada históricamente del sultán de Marruecos, según afirmaban. Por otra parte, debe reconocerse también que el Frente Polisario no habría sobrevivido ni combatido sin ayuda externa, notablemente procedente de Argelia y Libia.

Cuarto mito: la guerra de la corona alauita. El papel predominante del rey Al-Hasan II en la evolución del conflicto dió siempre la impresión de una guerra particular para aunar criterios y alejar contestaciones internas. Pero si la corona marroquí se aferró a la reivindicación como la salvaguarda tras los atentados del 71 y 72 , y se proyectó la Marcha Verde como la idea del rey unificador, lo cierto es que la anexión del Sáhara estaba en la ideología del partido Istiqlāl desde el 56 en el mapa del Gran Marruecos de ${ }^{\mathrm{C}}$ Allāl al-Fāsī, e incluso Muhammad V ya se había aferrado a la idea ante presiones populistas. Como en tantas otras ocasiones, el buen saber hacer estratégico del desaparecido rey marroquí estuvo a la altura de las circunstancias, pero no parece que fuese el creador de las mismas. Como afirma el propio Damis, Hasán <resultó ser> un hombre obligado a montar un tigre ${ }^{4}$, un tigre en cualquier caso vitalizado pese a la técnica del aburrimiento negociador ante las 135.000 alegaciones al censo de la ONU presentadas por el régimen del actual monarca Muhammad VI y la respuesta del Frente Polisario en el sentido de reanudar los enfrentamientos armados tras los incidentes del rallie París-Dakar 2001.

\footnotetext{
${ }^{4}$ Damis, John: "The Western Sahara Conflict...", pág. 174.
} 
Miguel Hernando de Larramendi recoge la consideración de Mustafa Sehimi sobre la acción independiente de la Corona en materia de política exterior, calificando tales prerrogativas de privilegios de competencia extraconstitucional ${ }^{5}$. Se trata de la personalización de la política exterior de la que habla Thérèse Benjelloun ${ }^{6}$, patente en el reinado de Hasán II y sin movimiento en contra del actual régimen. Los famosos discursos reales del 6 de noviembre conmemoraron el inicio de la Marcha Verde del 76, y el acto de sumisión y fidelidad al rey, la bay'a -piedra de toque en el dictamen del Tribunal Internacional de Justicia de La Haya- se ha exigido públicamente de la población del Sáhara al menos en cuatro ocasiones $(1979,1980,1985$ y 1991). El relanzamiento de la reivindicación sobre el Sáhara Occidental a partir de 1972 había servido al anterior rey marroquí para transformar la contestación interior (dos intentos de magnicidio) en reivindicación exterior. Es la presión maximalista de la que habla el mismo Hernando de Larramendi en su magnífico capítulo "El consenso sobre la marroquinidad del Sáhara Occidental"7.

Quinto mito: los factores económicos del conflicto. Desde un lado se afirma que el interés marroquí reside en las reservas de fosfato de Bu Craa, y desde el otro que Argelia buscaba el corredor atlántico para exportar ingentes cantidades de hierro. Pero los antiguos planes quiquenales argelinos siempre contemplaban la salida al Mediterráneo con la tranquilidad de una suficiente producción nacional, y la versión de los fosfatos marroquí es menos creible aún, ya que ante la remota posibilidad de que en el Sáhara Occidental hubiese una reserva de 2'2 billones de toneladas de fosfato, en el interior de sus fronteras reconocidas hay 16 billones, por lo que no supondría más que un -políticamente- incómodo excedente.

Sexto mito: el desgaste económico dell conflicto; que desde Rabat podría haberse ido buscando una solución política ante el elevado coste de la guerra. Pero es demonizar en exceso a Marruecos, siendo cierto que, además, al parecer no ha sido tan gravosa ya que en los años de enfrentamiento más cruento las monarquías del Golfo habrían estado financiando hasta el $60 \%$ de unos gastos de armamento americano y francés. Se habla incluso de fortunas de líderes africanos a cambio de cuerpos pretorianos marroquíes de élite entrenados en Francia. Los desequlibrios presupuestarios marroquíes probablemente han tenido las mismas causas macroeconómicas que el resto de los países árabes no productores de petróleo, y no excusivamente por razones bélicas. Lo que, en lectura distinta, no va en descrédito de Marruecos al lanzarse a la arena política internacional para solucionar un conflicto que puede permitirse militarmente.

Séptimo mito, y contrario al anterior: el desgaste militar del Polisario; que la lucha por el Sáhara independiente irá quedándose sin militantes por lo limitado de los asentamientos de Tinduf. Pero existen fríos cálculos, desde los peores años, de poder permitirse alrededor de

${ }^{5}$ Hernando de Larramendi, Miguel: La Política exterior de Marruecos. Madrid: Ed. Mapfre, 1997, pág. 82.

${ }^{6}$ Benjelloun, Thérèse: Visages de la diplomatie marocaine depuis 1844. Casablanca: EDDIF, 1991, 192 y ss.

${ }^{7}$ Hernando de Larramendi, págs. 138-147. 
mil bajas anuales, que sumado a los años sin graves enfrentamientos y a las admitidas posibilidades de reclutamiento en Mauritania, Malí o Níger, hacen prever que el Polisario siempre podría cumplir su amenaza de volver a la lucha armada si no se reanuda el proceso del referendum, sin contar siquiera con una hipotética causa común de la latente contestación beréber en todo el norte de África.

Octavo, último, y mito más relevante; la gran falacia: la piedra fillosofal del referendum. La trampa en la cuestión del Sáhara Occidental es basar todas las esperanzas de resolución en la mera celebración del referendum. Si no hay acuerdo final sincero en cuanto al censo, -no sólo entre Marruecos y el Polisario, sino las organizaciones regionales e internacionales ya implicadas-; si el referendum es desfavorable a alguna de las partes -y lógicamente lo será-, lo más importante será el día después. Después de tantos años, la solución no puede ser sustituir una guerra de descolonización por una entre vecinos soberanos y/o contestación autonómica.

\section{EL TERRITORIO Y LA HISTORIA.}

Ya Estrabón refiere en su Geografía que los gaderaitai (gaditanos) pescaban en las costas de la llamada Maurousía. Pero el punto de partida en el interés por el territorio puede datarse en el Convenio de Soria de 1291, el reparto de África entre Castilla y Aragón -semejante al de Tordesillas posterior con Portugal-. En 1346, el mallorquí Jaume Ferrer dijo haber llegado a Río de Oro (en realidad, Senegal), y desde finales del s.XIV se hizo patente la contínua presencia de naves castellanas -especialmente andaluzas- por esas aguas para conseguir esclavos. En 1449, el rey castellano Juan II concedía al duque de Medina Sidonia un amplísimo señorío sobre África. Por primera vez se hacía referencia a esa mar pequeña conocida en la época que se extendería desde Ifni a Cabo Juby. Y el primer asentamiento en la costa se remonta a cuando Diego García de Herrera construyó la fortaleza de Santa Cruz de la Mar Pequeña, al parecer en 1468. (En el Tratado hispano-marroquí de 1860 que daba fin a la guerra de África se reconocería esa ancestral presencia concediéndose el territorio de Ifni al pensarse que estaría ubicada allí, aunque estaría probablemente en la desembocadura del Uad Chebeica).

Después de Tordesillas (1494), Castilla se acercó al reino de los Bu Tata (Ifni). Lope Sánchez de Valenzuela, gobernador de Canarias, se adentraba en la costa africana con la intérprete María de Almuñécar y lograba la sumisión de los habitantes. Es la época de conquista mediante consentido vasallaje (Valenzuela llegó a ir a la mezquita tras el acuerdo) previa a tiempos menos contemplativos. Castilla perdió o abandonó Santa Cruz de la Mar Pequeña en 1524, terminando las entradas en África con el siglo XVI. Y es que la empresa africana facilitada por el poblamiento de Canarias había declinado en el s.XV, ya que el interés por América forzó a su olvido. Un caso aislado y sui generis sería el hecho africano posterior a la batalla de Alcazarquivir (1580): el nuevo soberano marroquí, Al-Mansur, encargó una 
expedición al sur a Joder Pacha ${ }^{8}$, almeriense raptado por los piratas y criado como musulmán. Joder Pacha atravesó el Sáhara conquistando Tombuctú y creando una ya imborrable presencia de andalusíes en la curva del Níger, abandonados a su suerte por el sultán de Marruecos.

En 1767 y 1799 se firmaban importantes tratados entre España y Marruecos que prueban la vacuidad de algunas razones históricas: al exigir España el rescate de los numerosos náufragos en la costa, Marruecos se desentendía al reconocer que sus dominios no abarcaban al sur del río Dra. Y al declinar el s.XIX volvería el interés, especialmente con la Conferencia de Berlín de 1884-1885, tras la que España retornaba al Sáhara. Poco antes, diversos exploradores españoles habían cruzado el Sáhara haciéndose pasar por musulmanes poniendo de manifiesto la existencia de un Bilād el-Siba: al sur del Dra el sultán de Marruecos no tenía ningún poder. Son los viajes de Joaquín Gatell en 1864 y el de Oskar Lenz con el intérprete español Cristóbal Benítez en 1880 llevando a cabo una expedición a Tombuctú. Al cruzar el Dra -límite norte de Tarfaya, el país de la tribu Tekna libre- relataban nuevamente que allí concluía la raza beréber y empezaba la nómada.

La ocupación española del territorio se produciría entonces, por las razones que Diego Aguirre relata: la vía libre de la Conferencia de Berlín de 1884 (reparto de África entre potencias europeas); la defensa estratégica de Canarias; los lógicos intereses pesqueros; y el apoyo del gobierno de Cánovas a sociedades africanistas y colonialistas. En 1884, serios intentos ingleses de instalarse en la costa saharaui movían a la Sociedad Española de Áfricanistas y Colonialistas a preparar una expedición en cinco días. La Sociedad Geográfica de Madrid promovía la creación de la Compañía Mercantil Hispano-Áfricana, domiciliada en Sevilla (con capital de empresarios que crearían después la Trasatlántica), y al frente de la expedición se destacó a Emilio Bonelli Hernando, futuro Comisario Regio. Bonelli llegó a acuerdos con los saharauis del litoral, los llamados moros de marea, y se consumó la anexión de los territorios entre Cabo Bojador y Cabo Blanco por parte de José Alvarez Pérez, llegándose a acuerdos con las tribus Izarquien y Erguibat-, y por la trascendente expedición Cervera-Quiroga-Rizo, organizada en 1885 por la Sociedad Española de Geografía Comercial, cuyo director de exploraciones no era otro que Joaquín Costa. Se iba robusteciendo la presencia española en la costa, menospreciando el interior.

Se remontan a esta época las primeras relaciones con el autoproclamado Mahdī -guía espiritual-Ma al-Ainin ( $m \vec{a}$ al- ${ }^{c}$ aynayn; agua de mis ojos $\left.{ }^{9}\right)$. En 1889, éste acampaba en lo que sería Smara y aceptaba la presencia española para parar el avance francés. El poder espiritual y temporal del cheij $\mathrm{Ma}$ al-Ainin no admitía dudas en cuanto a su independencia del norte, reforzada además por la Convención hispano-francesa de 1912: la frontera entre el límite

\footnotetext{
${ }^{8}$ Se suele suavizar la impresión del nombre transcribiéndolo del árabe (/Yuder/), pero lo cierto es que el mote le vino dado según una versión por sus habituales imprecaciones, y según otra por leyendas que darían al traste con su pretendida condición de eunuco.
}

9 Sola, Emilio: Sahara Occidental: Viaje al país de la esperanza. Madrid: Molinos de Agua, 1981, 21 y ss. 
sur del protectorado francés y el territorio español se situaba en el Uad Dra, frontera natural del desierto; límite sur del territorio del sultán marroquí.

Con todo, la ocupación real del territorio por parte de España, en virtud de su adjudicación el los tratados internacionales, se produciría en 1916, año en que Francisco Bens ocupaba Cabo Juby. la colonización de Francisco Bens (que escribiría sus memorias en Veintidós años en el desierto) incluían la ocupación de Cabo Juby (1916) y de La Güera (1920) acompañado siempre de nativos relacionados con los $\mathrm{Ma}$ al-Ainin. Se ponían también de manifiesto las buenas relaciones con los franceses al sur, que llegaron a imponer a Bens la Legión de Honor por un rescate de rehenes franceses.

En 1926 se creaban las primeras unidades indígenas en el Sáhara, y desde 1932 se desprestigiaba el territorio por su uso para deportaciones políticas que se continuarían hasta después de la guerra civil española. En la importante expansión de 1934 se tomaba Ifni y tenía lugar la simbólica sumisión de la familia Ma al-Ainin. En el 38, Antonio de Oro fundaba ElAaiún consolidándose el eje costero Ifni-Tantan-Cabo Juby-Aaiún-Smara-Villacisneros-Güera. Se ponía así de manifiesto la dificultad del interior y se consumaba el primer gran error estratégico español: se vinculaba jurídicamente el sur del Protectorado al Sáhara, Y decimos error estratégico porque con la independencia marroquí sería difícil trazar una nueva línea en lo que había sido deslindado, pese a la marcha atrás de 1947 en que se consideraban Ifni y Sáhara como entidades legales desvinculadas del Protectorado.

Desde 1941, las expediciones científicas empezaban a encontrar minerales y fosfatos, especialmente un año después, por el geólogo Manuel Alía Medina. (En 1962 se crearía ENMINSA (Empresa Nacional Minera del Sáhara) por el descubrimiento de los importantes yacimientos de Bu Craa). Y en 1954, la expedición antropológica de Julio Caro Baroja atraía la atención sobre las peculiaridades étnicas del territorio: se encuentran tres clases diferenciadas, cada una con sus subgrupos. En primer lugar los ARAB, descendientes de los árabes Maquil, llamados los ahl mdafa ("los hombres del fusil"), combatientes orgullosos; los CHORFA, descendientes de Mahoma; y los ZUAIA, ahl al-kutub (jurisconsultos y letrados). Como segundo escalafón, los AZNAGA, o zenetas; tribus tributarias de otras y dedicadas al pastoreo, pesca o agricultura; los MALEMIN, artesanos probablemente de origen judío; y los IGGAUEN, bardos o trovadores. Y en la base de la pirámide social, los ABID, esclavos negros; y los HARATIM, libertos. (España respetó tal estratificación social, e incluso en el célebra censo de 1974 se hace referencia a 3.018 llamados eufemísticamente "hijos adoptivos y parientes pobres" para no hablar de esclavitud ${ }^{10}$.

\footnotetext{
${ }^{10}$ Diego Aguirre, pág. 501.
} 


\section{EL GRAN MARRUECOS DE ${ }^{\mathrm{A}}$ ALLĀL AL-FĀSİ.}

En 1956, con la independencia de Marruecos, se creaba el África OCCIDENTAL ESPAÑOLA (AEO) con capital en Sidi Ifni. Tarfaya no se había entregado aún, y hasta 1957, Marruecos no reclamaría Ifni. 'Allāl al-Fāsī, líder del partido Istiqlal marroquí, había participado en 1947 en la creación del Comité pour la libération du Maghreb Arabe. Consumadas las independencias locales y desestimado un gran estado magrebí de Túnez a Mauritania, 'Allāl al-Fāsī transformó su nacionalismo pan-magrebista en marroquí: convirtió la idea del "Gran Magreb" en la del "Gran Marruecos", fácil transposición lingüística en árabe pues ambos se dicen magrib. "Marruecos linda al Sur con Senegal", afirmaría, configurando su hermano Abdelkabir el famoso mapa del hinterland mítico marroquí.

Desde 1956 penetraban en el Sáhara las bandas armadas del llamado Ejército de Liberación, inspirado por la ideología del Istiqlal y dirigido por Ben Hammu. España accedía a su penetración en el territorio creyendo, absurdamente, que pretendían tan sólo empujar a Francia en Argelia y la actual Mauritania. El principal suministrador de armamento sería el comerciante marroquí Ali Boaida, futuro gobernador marroquí de Tarfaya. La diatriba española se hacía patente: si actuaba contra el Ejército de Liberación, se ganaba la enemistad de Marruecos favoreciendo a Francia, la republicana. Había también una larga enemistad comercial con París: la sociedad francesa MIFERMA (Minas de hierro de Mauritania) había construido el tren del mineral sin descargar en el mar por territorio español ${ }^{11}$. Pero los saqueos y la propaganda (a favor del Istiqlal) de las bandas del Ejército de Liberación, se hacían insostenibles en todo el Sáhara, en la zona francesa, y muy especialmente en Sidi Ifni, que fue atacado en 1957. Esa fue la razón militar de las célebres operaciones conjuntas hispanofrancesas ÉCOUVILLON y TEIDE de 1958.

Una vez concluidas tales operaciones de castigo, el rey Muhammad V acudía al oasis de M'Hamid, sobre el río Dra, donde pronunció un primer discurso sobre el retorno de nuestro Sáhara. Se había rentabilizado políticamente el intento del Ejército de Liberación: si hubiese triunfado, la corona se habría puesto a la cabeza, pero una vez fracasado, se neutralizaban elementos potencialmente subversivos y se recogía su popular bandera. El saber hacer estratégico de la corona marroquí daba sus primeros pasos hacia el sur haciendo Muhammad V suyas las reivindicaciones territoriales del partido Istiqlal, que propugnaba las tesis de ${ }^{\mathrm{c}}$ Allāl al-Fāsī sobre "el Gran Marruecos" lindando al sur con Senegal. En las ofensivas militares europeas, había sido prácticamente destruido el anexionista Ejército de Liberación Nacional marroquí y pretendidamente saharaui. Francia, por su parte, había consolidado así el territorio de Mauritania, garantizando su independencia en 1960.

A partir de ese año, tras la admisión de Mauritania en la ONU, Marruecos limitaría su reivindicación territorial al Sáhara Occidental, comenzando su renuncia al oriental, argelino

\footnotetext{
11 Véase el magnífico estudio de Javier Morillas: Sahara Occidental. Desarrollo y subdesarrollo. Madrid: Prensa y Ediciones Iberoamericanas, 1990, pág. 269 y ss.
} 
(región de Tinduf -aún mediaría una guerra-), y al propio territorio mauritano, mejorando así las relaciones entre Rabat y los Estados africanos. Aún así, si bien a partir de 1969 el reconocimiento marroquí del Estado mauritano mejoraba sus relaciones con el sur, entre 1976 y 1988 Marruecos no mantuvo relaciones diplomáticas con Argelia por la cuestión del Sáhara Occidental y los consiguientes problemas de delimitación de frontera. Sólo en 1989 ratificaría el Parlamento marroquí el acuerdo con Argelia admitiendo la intangibilidad de las fronteras coloniales, y dando fin al enfrentamiento que en 1963 había dado lugar a la llamada Guerra de las Arenas entre ambos estados.

Si en el 58 Francia forzaba el futuro reconocimiento de Mauritania, España reconocía en parte las aspiraciones marroquíes pretendiendo consolidar las limitadas fronteras del Sáhara entregando la franja de Tarfaya -no así aún Sidi Ifni-. Tras la entrega, se sucedieron sublevaciones de los Erguibat contra el régimen de Rabat. (Despúes resultaría sintomático el hecho de que líderes carismáticos del Frente Polisario fuesen oriundos de esta región, reflejo del desacuerdo de parte de la población a la incorporación. Marruecos, no obstante, haría uso de tales ascendencias para demostrar que el problema del Sáhara no es más que de rebeldía ${ }^{12}$ ). En 1958 se llevaba también a cabo la provincialización de Ifni y Sáhara Español tratando, como recuerda Diego Aguirre, de calcar el modelo portugués salazarista al convertir las colonias en provincias para consolidar así su vinculación a la metrópolis ${ }^{13}$.

En 1961, Al-Hasan II sucedía a su padre Muhammad V en el trono, vinculándose ya para siempre la corona a las reivindicaciones territoriales. El espíritu del brazo armado de la reivindicación, el antiguo Ejército de Liberación, sería recuperado por el llamado Frente de Liberación del Sáhara (FLS) en 1966, que reaparecería en el 75 como Frente de Liberación y Unidad (FLU), o incluso como FLUS (del Sáhara) o el MOREHOB (Mouvement de Résistance des Hommes Bleus) de Édouard Moha ${ }^{14}$.

Desde 1955, España formaba parte de las Naciones Unidas, y debería aceptar en 1960 la Res. 1514 (XV); la llamada Declaración sobre la concesión de la independencia a los países y pueblos coloniales. En 1968 se concedería la independencia de Guinea, y en 1969 la retrocesión de Ifni a Marruecos a cambio de importantes garantías y ventajas pesqueras. Marruecos, no obstante, denunciaría en 1972 tales acuerdos, por lo que Ifni fue, a la postre, un capítulo más.

\footnotetext{
12 Acerca de la hipótesis de una creación argelina del revolucionario Polisario, cuando nació entre los independentistas de Tarfaya, el propio Juan Goytisolo serviría de portavoz del régimen en su defensa de la marroquinidad del Sáhara. (Véase: Goytisolo, Juan: "Témoignage". En: HASSAN II (prés.): La Marche Verte. Paris: Plon, 1990, 61-66).

13 Diego Aguirre, pág. 448.

${ }_{14}$ Véase: Moha, Édouard: Les relations hispano-marocaines. Deux royaumes aux multiples affinités. Casablanca: EDDIF, 1994. (Págs. 83-105 para su versión sobre la cuestión del Sáhara).
} 


\section{INDEPENDENCIA Y REFERENDUM.}

El censo español de 1974 arrojaba un cifra de 74.904 habitantes del territorio, en la que ya se incluyía 1.405 no saharauis. Las tres sombras protectoras del pueblo saharaui serían la citada Res. 1514 (XV); el llamado Comité de los 24 creado en 1962 para velar por la independencia de los territorios coloniales; y la IV Comisión de descolonización.

En realidad, la que Diego Aguirre denomina traición de España al pueblo saharaui no es imputable a todos los sectores con capacidad decisoria por igual. De hecho, la clave para entender los vaivenes de la política española en el Sáhara es el enfrentamiento entre el ministro de Exteriores, Castiella, y los sectores más reaccionarios del régimen. Para Castiella, España se hallaba comprometida en el camino de la descolonización, frente a la teoría del presidente del gobierno Carrero Blanco, de ser preferible un Sáhara marroquí a uno independiente. Por otra parte, el general Muñoz Grandes, vicepresidente del gobierno, y el ministro José Solís, mantuvieron conversaciones con ${ }^{\mathrm{c}} \mathrm{Allāl}$ al-Fāsī tendentes a la misma postura. Las corrientes más integristas del régimen contemplaban a Marruecos como el viejo aliado en la guerra civil para el bando ganador, e incluso en los últimos tiempos se produjo un entendimiento entre Franco y Al-Hasan II, puesto de manifiesto muy especialmente con el llamado espíritu de Barajas, por la cordialidad con que ambos se encontraron en tal aeropuerto en 1963. El enfrentamiento entre los intentos de conciliación internacional del ministro Castiella y el inmovilismo del presidente del gobierno Carrero Blanco produjeron el cese de Castiella y su sustitución por López Bravo, más próximo a Carrero y exponente de la tecnocracia de tinte confesional que se hizo con el poder tras el asunto Matesa de 1969. Estados Unidos recibía la noticia del cese de Castiella con regocijo, pues el ministro que nombrase a García Gómez embajador se había caracterizado por una apertura al mundo árabe y una postura crítica a las bases norteamericanas en territorio español. Los hombres del régimen como Muñoz Grandes, Solís Ruiz, Carrero y López Bravo, demostrarían que actitudes contemporizadoras como la de Castiella no habían encontrado aún su tiempo. Sin convertirle desde aquí en el paladín de la pre-transición española en el exterior, sí al menos cabe destacar no sólo su templada idea de la política exterior de España, sino los nombres que irán surgiendo de entre los diplomáticos de su entorno, como Fernando Morán o Emilio Casinello.

Desde el cese de Castiella en 1969, las decisiones sobre el Sáhara se tomarían desde Presidencia del Gobierno, y la mejor prueba del enfrentamiento en Madrid es que, sorprendentemente, en la resolución aprobada ese año sobre el Sáhara -la 2591 (XXIV)-, España se abstuvo, cuando venía votando afirmativamente en las cinco anteriores del mismo talante. Ese mismo año, Marruecos reconocía diplomáticamente a Mauritania, con lo que el mapa mítico de ${ }^{\mathrm{C}}$ Allāl al-Fāsī se reducía concentrándose en el Sáhara, en contra de la voluntad mayoritaria de los saharauis. Y es que en el proceso de entrega del territorio, se comprueba lo que ya se hizo patente desde los tiempos de Ma al-Ainin: que la población aceptaba la presencia española como un mal menor frente a las corrientes anexionistas marroquíes y en segundo término de Mauritania -para quien, en el fondo, la presencia española era una garantía frente a la expansión marroquí-, y que al control español sólo podía sucederle la independencia. 
El momento preciso para que una España madura internacionalmente hubiese procedido a la celebración del referendum para garantizar la independencia del Sáhara -de haber tenido una voluntad real al respecto- era en 1971 o 72, aprovechando la dispersión de la política marroquí como consecuencia de los atentados al rey y el proceso de Kenitra. Solucionado el conflicto interior, la monarquía marroquí volvería al exterior con la necesidad de aunar voluntades, y allí estaban el Sáhara y un Madrid obsoleto. En la diatriba entre preparar al Sáhara para la independencia, como había hecho Francia con Mauritania, y entregarlo, venció la segunda, y probablemente no sólo por la tendencia entreguista del final del régimen de Franco, sino por esa lacra tradicional de pensar que los problemas se irían solucionando por sí solos. Frente a este desdén español, a Marruecos le movían tres poderosas razones; rechazar un Sáhara independiente pro-argelino, los posibles beneficios económicos de la incorporación del territorio, y la importante baza de aglutinar al pueblo en torno al rey.

\section{LA PRESIÓN MARROQUÍ.}

Desde el acceso a la independencia de Argelia en 1962 y la toma de posesión de Tinduf, en su frontera sur occidental con Marruecos, éste encontraría una nueva fuente de problemas al ser desfavorable para Rabat la delimitación de fronteras llevada a cabo por la colonización, las líneas Varnier y Trinquet. El problema fronterizo provocó la citada guerra entre Argelia y Marruecos de 1963 y a su conclusión sin trascendencia se debe la aceptación del espíritu de la OUA (Organización para la Unidad Áfricana) referente a respetar las fronteras coloniales como mal menor. Sólo en 1970 abandonaría Marruecos su reivindicación sobre Tinduf, en lo que subyace un deseo de que Argelia no tomase partido a favor de la independencia del Sáhara. El deseo marroquí siempre sería por entonces tratar la cuestión del Sáhara exclusivamente con España. Y el error estretégico española fue no tratar la cuestión exclusivamente con el pueblo saharaui.

En 1978, Rabat se reforzaba internacionalmente al firmar con la Unión Soviética el acuerdo de Meskala por el que le suministraría fosfatos marroquíes. Tal acuerdo había sido congelado tres años antes debido a la posición de Moscú favorable a las reivindicaciones argelinas en la ONU, sirviendo tácitamente, por tanto, para neutralizar el apoyo soviético al Frente Polisario. En 1979 Marruecos se anexionaba Rio de Oro -el sur saharaui- tras la retirada mauritana de la zona como consecuencia del cambio de gobierno en Nuakchott tras el golpe de Estado que apartó del poder a Mujtar Uld Dada. En Rabat se creaba el llamado Consejo Especial para la Preservación del Sáhara Marroquí con la participación de todos los partidos políticos parlamentarios, reforzado a partir de 1981 por el Consejo Consultivo Real para Asuntos del Sáhara, integrado por los llamados diputados del Sáhara. Este segundo órgano se revitalizó en 1991 ante la presión internacional conducente al referendum. Incluso el antiguo partido comunista se alineaba con la corona: cuando en 1974 fue legalizado tal partido, con el nombre de Partido del Progreso y del Socialismo, su propio dirigente Ali Yata fue encargado de defender las tesis marroquíes entre los países del Este en un curioso quid pro quo entre legalización y pragmatismo. 


\section{EL FRENTE POLISARIO.}

Desde la Carta abierta del pueblo saharaui al Gobernador General -español- a la actividad abierta del Frente Polisario, los saharauis irían tomando conciencia de que España no iba a facilitar la independencia ni convertirles en una provincia de facto. Pese a los logros de sedentarización (se consolidó la figura del cheij fortalecida por la tradición y el reconocimiento por parte de España después de ser elegido por la propia tribu), y los serios intentos de vertebrar la sociedad saharaui creando sus propios órganos desde policía o ayuntamientos hasta la Yemaa o Asamblea Popular, es comprensible que Madrid no concediese al Sáhara unos derechos políticos de los que ni siquiera disfrutaba la metrópolis, y probablemente en ese punto se alzó el pueblo saharaui. Bassiri, fundador de lo que después sería el Frente Polisario, en realidad no había creado un movimiento revolucionario, sino una agrupación que en principio dirigió sus reivindicaciones a una tutela española de diez o quince años previa a la independencia. La respuesta de España provocaría su radicalización y su búsqueda de apoyo en Argelia o Libia. Bassiri rechazaba la representación de títeres de la Yemaa y reivindicaba la frontera norte del Sáhara en el río Dra. En otras palabras, reclamaba la provincia ya marroquí de Tarfaya como territorio de un Sáhara independiente a medio plazo. (El tiempo daría la razón a Bassiri en su desconfianza hacia la Yemaa: el presidente de la misma, Jatri Uld Said, sería el primero en rendir pleitesía al rey marroquí en el 75).

Cuando en 1970 se produjeron los altercados de Jatarrambla, la organización comenzó a moverse contra España en primer término, transformándose en el Frente Polisario en 1973. Con el tiempo en contra, España preparó un borrador de lo que sería un estatuto de autonomía, el Estatuto del territorio del Sáhara en 1974, pero nunca se promulgó por la enfermedad de Franco, probablemente la excusa esperada para no tomar una decisión. En un intento de última hora, y comprobado el tirón inicial del Polisario, la máxima autoridad española en el Sáhara, coronel Rodríguez de Viguri, ideó la creación del efímero Partido Unificado Nacional del Sáhara (PUNS). Madrid estaba menospreciando la fuerza del Polisario, tildado de procomunista y revolucionario -las declaraciones del Polisario de apoyo a ETA, por ejemplo, tampoco permitía romper etiquetas alegremente-.

\section{EL DICTAMEN DEL TRIBUNAL DE JUSTICIA DE LA HAYA.}

Cuando España anunció en 1974 que celebrará al año siguiente un referendum de autodeterminación en el Sáhara, Marruecos se vió obligado a actuar rápidamente. El censo estaba preparado, y Madrid dispuesto a aceptar todas las resoluciones de la ONU sobre el Sáhara. Desde el verano de 1974, la campaña anexionista de Marruecos se reforzó por varias razones: se sospechaba, en pura lógica, que España avanzaba hacia la autodeterminación del territorio por el anuncio del referendum; Franco se hallaba gravemente enfermo y Madrid no podría actuar con una mínima resolución exterior; el Polisario iba creciendo en detrimento del discurso pro-marroquí; Portugal había perdido su imperio creándose nuevos estados, lo que 
podría ser un precedente internacional para el Sáhara que no podía aceptar Rabat; la atención internacional se desplazaba desde Oriente Medio atenuado el conflicto del 73 y se centraba incómodamente en el Sáhara, y por último, Marruecos podía permitirse acciones medianamente hostiles ya que contaba con el apoyo incondicional del nuevo presidente francés, Giscard D'Estaign y tácitamente de Estados Unidos, mucho más favorable a un Sáhara marroquí que pro-argelino, esto es, en la órbita soviética ${ }^{15}$.

En definitiva, España pensaba, con las reticencias propias de la vejez del régimen, que el Sáhara debía ser independiente, pero tras anunciar el referendum advirtió que sólo iba a ser posible con apoyo militar español contra la opinión de Francia y Estados Unidos. ¿Qué podía hacerse?. Por añadidura, el gobierno de Arias Navarro jamás habría transferido el poder a un gobierno revolucionario, y tal era la imagen del Polisario -que en nada se ocupó de transformar-, cuando quizá habría sido más sencillo e inteligente moderar a un Frente Polisario que engrosaban los estudiantes saharauis de Canarias y Madrid, siendo relevante el grupo del Colegio Mayor Virgen de África en la capital. Pero el gobierno español prefirió aprovechar estos cauces para la creación del fantoche y efímero PUNS, desintegrado por la reiterada huida a Marruecos de sus líderes con los fondos del partido. España dejaba para la Historia el interrogante de si habría creado el PUNS para entregar a Marruecos la población del Sáhara, o si simplemente estaba jugando a las colonias con maniobras francesas que habían fracasado hacía ya diez años.

Viendo Marruecos limitada su capacidad de movimiento, y obligada a actuar según vemos, decidió una última maniobra para paralizar la celebración de un referendum que demostraría la determinación del pueblo saharaui de no pertenecer a Marruecos: recurrió al Tribunal Internacional de Justicia de La Haya: si se demostraba que el Sáhara era tierra de nadie (terra nullius) cuando España lo ocupó, Rabat aceptaría el referendum. La inteligencia de la maniobra es desbordante: en primer lugar porque la aceptación o no del referendum por parte de Rabat no era en sí vinculante y de este modo lo parecía; en segundo lugar porque así se saltaban seis resoluciones de la $\mathrm{ONU}^{16}$ creando la impresión de que el asunto del Sáhara acababa de empezar; y en tercer lugar, y lo más importante, porque España jamás argumentó que el Sáhara fuera terra nullius cuando lo ocupó, sino que sus habitantes tenían unas estructuras de poder desvinculadas de Marruecos. El objetivo final de Rabat era conseguir para el Sáhara un estatus internacional similar al que Indonesia había logrado para Nueva Guinea: su antigua metrópoli, Holanda, abandonaba el territorio dejándolo a cargo de Naciones Unidas que a su vez encargaba de su tutela a Indonesia durante el tiempo suficiente para preparar un referendum que consolidase su reincorporación de iure al territorio que pretendía su anexión.

15 Véase el certero análisis de Diego Aguirre (pág. 636 y ss.).

${ }^{16}$ Resoluciones relativas a la independencia y referendum del Sáhara Occidental hasta la fecha del censo español: 1514 (XV) de 1960; 2072 (XX) de 1965; 2229 (XXI) de 1966.; 2354 (XXII) de 1967; 2428 (XXIII) de 1968; 2591 (XXIV) de 1969; 2711 (XXV) de 1970; 2983 (XXVII) de 1972; 3162 (XXVIII) de 1973; 3292 (XXIX) de 1974 (aplazamiento del referendum hasta el dictamen del Tribunal Internacional de Justicia). 
En cualquier caso, a España le sobrepasaba la maquinaria estratégica marroquí, siempre varios pasos más allá de los asuntos que se dirimían. Con una inusitada inocencia internacional, Madrid se afanó en recopilar una inmensa documentación histórica para defender lo insustancial, en lugar de aferrarse a las resoluciones de la ONU sobre el derecho de los pueblos a su libre determinación y celebrar un referendum sin contemplaciones a tenor de lo observado por la misión de la ONU en su visita al territorio de 1975 -ofrecida por el embajador español ante la ONU, Jaime de Piniés-, asombrada por la aceptación popular del Frente Polisario y el rechazo a Marruecos. Cuando La Haya dictaminó que Marruecos no tenía ninguna autoridad al sur del Dra, pero que algunas tribus habían proclamado su bay'a o pleitesía al sultán de Marruecos como autoridad religiosa, Rabat anunció lo que habría anunciado fuera cual fuese el dictamen; que una multitud de marroquíes atravesarían la frontera para tomar posesión del territorio.

\section{LA MARCHA VERDE.}

Hoy resulta indiscutible el asesoramiento norteamericano a la marcha anunciada en octbre del 75, inmediatamente después del dictamen de La Haya. Estados Unidos y Francia apoyaron la Marcha Verde, reticentes a un Polisario pro-soviético. Diego Aguirre y Criado recogen el telegrama enviado por el Secretario de Estado norteamericano, Henry Kissinger, a Rabat, apoyando la marcha: Laissa podrá andar perfectamente dentro de dos meses. El la ayudará en todo ${ }^{17}$. Tras la Marcha Verde, Argelia denunciaría la política marroquí y mauritana de hechos consumados apoyada por Francia y Estados Unidos ${ }^{18}$.

Fueron 350.000 hombres los agrupados en Tarfaya el 3 de noviembre de 1975 para pasar la frontera hacia el sur y tomar el Sáhara. El gobierno español aceptó tácitamente la entrada en unos diez kilómetros, punto en que la Marcha volvió habiendo conseguido su simbólico objetivo. Un día antes del anuncio de la marcha, Madrid ya había aceptado la cesión del territorio y organizado la opoeración militar Golondrina desde Canarias: abandonar incluso antes de que se pronunciase La Haya. Rabat llegó a desestimar el llamado Plan Waldheim, por el Secretario General de la ONU, que contemplaba una salida española y administración internacional hasta el referendum, plan desarrollado por el enviado especial André Lewin. Era innecesario y contraproducende, sabiendo la decisión entreguista de Madrid.

La Marcha, por tanto, no forzó la retirada, sino que aprovechó su conocimiento previo y la rentabilizó popularmente. La política abandonista de España había llegado a silenciar contactos con el mismo responsable del Polisario, Lulei (El Ueli Uld Mustafa). El 14 de noviembre de 1975, se firmaban los Acuerdos de Madrid entre los representantes de España, Marruecos y Mauritania. En la entrega del territorio "se tenía en cuenta" la voluntad popular

17 Diego Aguirre, pág. 792, y Criado, Ramón: Sahara. Pasión y muerte de un sueño colonial. París: Ruedo Ibérico, 1977, pág. 213.

${ }^{18}$ Hernando de Larramendi, pág. 330. 
en el artículo III de los acuerdos tripartitos: será respetada la opinión de la población saharaui a través de la Yemaa, ficción continuada hasta la citada deserción del presidente de la misma, Jatri Uld Said. Si bien los acuerdos deberían ser considerados nulos ante la imposibilidad de que España cediese un territorio sin que éste pasase a estar bajo la administración de la ONU, ésta tampoco entraría a discutir un pacto entre las partes, por más que se hubiese hecho caso omiso a la obligatoriedad del referendum. También se pasó por alto la paradoja de la desprovincialización; cómo Madrid podía decidir que una provincia dejase de serlo, así como el informe negativo del enviado especial de la ONU, Olof Eydbeck, manifestando sus serias dudas al compromiso de las partes de celebrar la consulta popular dado el sentimiento anti-marroquí de los saharauis. Por lo que a Francia respecta, la presidencia de Giscard d'Estaing apoyó los acuerdos de Madrid y se negó al reconocimiento del Frente Polisario, mientras Marruecos se iba convirtiendo en el principal perceptor internacional de ayuda francesa, flujo que se equilibró con Argelia posteriormente con el gobierno Mitterrand. En 1982, el Frente Polisario llegaba a abrir una oficina en París, y el descontento marroquí con Francia -en esta cuestión- se intensificó con la visita de Danielle Miterrand al campo de refugiados de Tinduf ${ }^{19}$. En cuanto al carácter tripartito de los acuerdos, si bien éstos contemplaban el reparto del Sáhara entre Marruecos y Mauritania,w tras el citado golpe de Estado en Nuakchott de 1979 y el Acuerdo de Paz mauritano-marroquí del mismo año, Mauritania se retiraba del territorio.

\section{LA GUERRA Y LA PAZ NEGOCIADA.}

En febrero del 76, el Frente Polisario comenzaba su acción en solitario sustituyendo la Yemaa por el CNS, Consejo Nacional Saharaui, órgano máximo de la República Arabe Saharaui Democrática, proclamada en Bir Lahlu el 27 del mismo mes. La primera misión del Polisario sería la evacuación hacia Argelia, en la región de Tinduf, de los campamentos de refugiados. En cuanto a España, si en 1979 el portavoz del grupo parlamentario socialista, a la sazón Felipe González, denunciaba los acuerdos de Madrid solicitando que fuesen declarados nulos, la lógica continuísta movió a que ni entonces ni durante los años de gobierno socialista se diese un paso más allá, siquiera simbólico. El rechazo del Polisario a los acuerdos tripartitos de Madrid se tradujo inmediatemente en acciones bélicas en primer lugar contra Mauritania, al sur, por ser considerada más vulnerable, fase del conflicto que concluyó en 1979 con la mencionada retirada mauritana del Sáhara y la cesión al Polisario de Tiris alGarbia. La obligada táctica defensiva en la guerra de desgaste marroquí alcanzó su apogeo en 1981 con la contrucción de los llamados muros de arena, estrategia del general Dlimi a partir de 1980 de construir una cadena de muros defensivos en el Sáhara (en 1987 ya se habían erigido más de 2.000 kilómetros con la consiguiente pérdida de maniobrabilidad para el Polisario). También en 1981, Rabat admitía la celebración del referendum de autodeterminación, si bien se planteaba claramente como mero trámite para confirmar la

19 Ibid, pág. 268. 
marroquinidad del Sáhara. La concesión era un golpe de efecto al hacerse pública en la cumbre de la OUA celebrada ese año en Nairobi, suscitando las críticas de la Unión Socialista de Fuerzas Populares de Marruecos y sin poder evitar ya que la organización africana admitiese en su seno a la RASD en 1984. No obstante, la aceptación marroquí del referendum obtuvo como contrapartida una más favorable actitud norteamericada. La administración Reagan, si bien mantenía la línea clásica no comprometedora de las administraciones anteriores, daba un paso más allá abandonando las restricciones en el suministro de armas argumentando que el alto el fuego y la solución negociada del conflicto no dependía en exclusiva de Marruecos. El deseo de internacionalización del conflicto por parte marroquí, escudándose en que se trataba en realidad de una guerra contra la Unión Soviética (por el apoyo argelino al Frente Polisario y sus conexiones con el Este), se derrumbaba con el muro de Berlín, y la administración Bush se mostraba partidaria de la resolución regional del conflicto.

En enero de 1989 se producía el histórico encuentro entre Al-Hasan II y los dirigentes saharauis en Marraquech, y en 1991 se acordaba el alto el fuego, así como que el referendum debería celebrarse en 1992. Ante la clara inoperancia de las soluciones bélicas, el reconocimiento de la necesidad de una solución negociada plantea el problema del referendum, que aparte de las cuestiones sobre fecha y censo, nada desdeñables, entraña la complicación de la fórmula que Maddy-Weitzman llama el ganador se lleva todo ${ }^{20}$. Los encuentros posteriores de Ginebra (junio de 1991 y noviembre de 1992), El Aaiún (1993), hasta el proceso seguido en Berlín en 2000 no servirían más que para abonar el terreno para el mayor progreso diplomático en la cuestión del Sáhara Occidental con el nombramiento del ex-secretario de Estado norteamericano, James Baker, como enviado especial para revitalizar la dormida presencia de la misión de paz de la ONU, MINURSO. Las reuniones de Londres y Lisboa (junio y agosto de 1997) por él apadrinadas desembocarían en el encuentro de Houston (septiembre del 97), reunión definitiva en la Universidad de Rice en que se acordó (¿una vez más?) la celebración del referendum en 1998 y, lo que no es menos importante, el número de votantes: 80.000 electores. Acercarse en tal medida al censo español (74.904), supone una concesión marroquí al desestimar su exigencia de 150.000 electores; concesión que hace temer la llamada tercera vía: que la pregunta del referendum no sea independencia o marroquinidad, sino un punto intermedio sin duda inaceptable a largo plazo. Se ha venido hablando incluso de una solución al estilo de Puerto Rico, estado libre asociado, propuesta marroquí a la galería, sin al parecer contacto directo con el Polisario como en el cambio del año 2000 a 2001 se hizo patente tras los poco fructíferos encuentros de Berlín.

Pero también debe haber lugar para las lecturas optimistas. Cuando se creó la Unión del Magreb Arabe (UMA) tras la firma del Tratado de Marraquech en 1989, el gobierno argelino aceptó la ausencia de la RASD como concesión a Rabat a cambio de la primera y citada

${ }^{20}$ Maddy-Weitzman, Bruce: "Conflict and conflict management in the Western Sahara: Is the endgame near?". Middle East Journal 45,4, (Autumn 1991), 594-607. 
entrevista de ese año entre el monarca alauita y representantes del Frente Polisario. Toda referencia al Sáhara Occidental quedaba excluída de los textos de una $\mathrm{UMA}^{21}$, en práctica inoperancia actualmente. Quizá una República Arabe Saharaui Democrática independiente e incorporada a tal organización regional pueda servir para activarla, acallado uno de sus mayores focos de conflicto. Y quizá esa tercera vía, esa temida dependencia de Marruecos temida ante lo inaceptable por parte del Polisario-, pueda diluirse en lazos mayores a escala magrebí; concesiones menores de soberanía en aras de una mayor integración supranacional, dando significado real a las tan traídas y llevadas soluciones regionales de los conflictos.

${ }^{21}$ Hernando de Larramendi, pág. 347. 